\title{
HIGH RESOLUTION POWDER BLAST MICROMACHINING
}

\author{
Henk Wensink, J.W. Berenschot, Henri V. Jansen, Miko C. Elwenspoek \\ MESA $^{+}$Research Institute, University of Twente, P.O.Box 217, 7500 AE Enschede, \\ The Netherlands, Fax: x31-53-4893343, Email: H.Wensink@tn.utwente.nl
}

\begin{abstract}
Powder blasting, or Abrasive Jet Machining (AJM), is a technique in which a particle jet is directed towards a target for mechanical material removal. It is a fast, cheap and accurate directional etch technique for brittle materials like glass, silicon and ceramics. By introducing electroplated copper as a new mask material, the feature size of this process was decreased. It was found that blasting with $9 \mu \mathrm{m}$ particles (compared with $30 \mu \mathrm{m}$ particles) result in a higher slope of the channel sidewall. The aspect ratio of powder blasted channels was increased by using the high resistance of the copper mask in combination with the use of $9 \mu \mathrm{m}$ particles. Furthermore, our measurements show how the blast lag (small channels etch slower compared to wider channels) is decreased by using smaller particles.
\end{abstract}

\section{INTRODUCTION}

Sand blasting is an old technique, which is used to remove paint, clean houses and decorate glass. Powder blasting, with small particles $(<100 \mu \mathrm{m})$, is used for e.g. device demarking in electronic industry, surface preparation prior to plating (without mask) but also rapid prototyping [2] and flat panel display production [1][3] (with mask). In research, powder blasting is widely used to determine the wear rate of industrial materials.
Powder blasting, or Abrasive Jet Machining (AJM), can also be used for mictomachining. Being an IC technology spin off, micromachining is best performed on silicon whereas other materials (e.g. ceramics) are much harder to process. Powder blasting is a directional etch technique for brittle materials like glass, silicon and ceramics. It is a fast process (etch rate approximately $25 \mu \mathrm{m} / \mathrm{min}$ on a 3" wafer with one nozzle) and the required equipment is relatively cheap.

A major goal of our project is to decrease the feature size to $10 \mu \mathrm{m}$ for powder blasting. To do so, a new suitable mask must be found. Also, it requires the use of an average particle size of at most a third of the desired channel width (as a rule of thumb). Sharp alumina particles $\left(\mathrm{Al}_{2} \mathrm{O}_{3}\right)$ are available in large quantity with any average size [11].

In this article we show new results with powder blasting by using a new mask material and different particle sizes. We concentrate on glass as the target material, but silicon and ceramics can be processed in a similar way.

\section{Glass Machining in General}

The difficulty of making structures in glass is reflected in the wide variety of non-conventional techniques for glass (micro) machining. Nonetheless, glass is becoming a popular construction material in e.g. microfluidics. Table 1 gives an overview of available glass machining techniques, and their

Table 1: An overview of glass (micro)machining techniques and their general capabilities.

\begin{tabular}{|l|l|l|l|l|l||}
\hline & Min. feature size & Maximum depth & Aspect Ratio & $\begin{array}{l}\text { Design definition } \\
\text { by mask }\end{array}$ & \begin{tabular}{c} 
Ref. \\
\hline Drilling
\end{tabular} \\
\hline Milling & $800 \mu \mathrm{m}$ & $>1 \mathrm{~mm}$ & 10 & No & {$[4]$} \\
\hline Laser & $500 \mu \mathrm{m}$ & $>1 \mathrm{~mm}$ & 10 & No & {$[4]$} \\
\hline Ultrasonic drilling & $100 \mu \mathrm{m}$ & $>1 \mathrm{~mm}$ & 25 & No & {$[4]$} \\
\hline $\begin{array}{l}\text { Electrochemical } \\
\text { discharge drilling }\end{array}$ & $75 \mu \mathrm{m}$ & $>1 \mathrm{~mm}$ & 10 & No & {$[5]$} \\
\hline Photosensitive glass & $50 \mu \mathrm{m}$ & $>1 \mathrm{~mm}$ & 15 & No & {$[6]$} \\
\hline Powder Blasting & $<50 \mu \mathrm{m}$ & $>1 \mathrm{~mm}$ & 20 & Yes & {$[4][7][8]$} \\
\hline HF etching & $1 \mu \mathrm{m}$ & $>1 \mathrm{~mm}$ & 2.5 & Yes & \\
\hline RIE etching & $0.5 \mu \mathrm{m}$ & $>1 \mathrm{~mm}$ & 1 & Yes & {$[9]$} \\
\hline
\end{tabular}


general capabilities. Complex designs can best be made when the structure is defined by a mask, which is not the case for different kinds of drilling and milling. The properties of photosensitive glass are optimized for a good pattern transfer, but not for other processes like silicon bonding. RIE etching in glass is limited by a slow etch rate.

We show in this article that with powder blasting, a small feature size and high aspect ratio can be obtained. It also has the advantage of fitting very well between the common micromachining techniques due to its lithographic masking, process similarities and compatibility. Furthermore, powder blasting is not only suitable for glass micromachining, but can equally well be used on a wide class of other materials. For the production of flat panel displays, powder blasting was judged to be the best process to create thousands of holes at once at low cost, high speed and with a high accuracy [1].

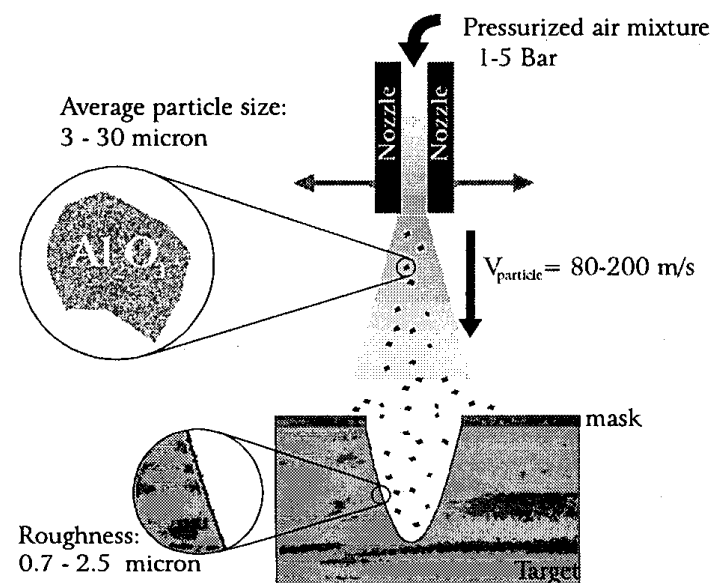

Figure 1. A schematic impression of the powder blast process

\section{POWDER BLASTING}

In powder blasting a particle jet is directed towards a target for mechanical material removal (Figure 1). Alumina particles are supplied to a high-pressure airflow by a vibrating feeder (in a HP-2, Texas Airsonics) after which they are accelerated through a nozzle. The particles hit the target with a speed of 80$200 \mathrm{~m} / \mathrm{s}$ in a box that is ventilated by a cyclone, which can separate the powder from the airflow. The target is covered by a mask and the nozzle is scanned over the target several times to achieve a uniform etched surface. Using a mask with powder blasting has several advantages. The particle jet (which is about $1 \mathrm{~cm}$ in diameter) can be optimized for etching, while the mask defines the small and complex structures. It also allows multiple jets to be used which decreases the process time. The flux rate of the

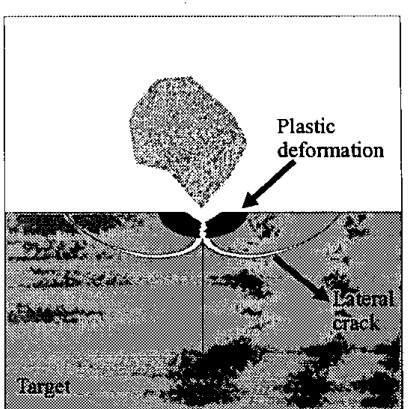

Figure 3. The etch mechanism of a sharp particle

particles is measured using a balance with an accuracy of 0.5 gram (Sartorius QC 34 EDE-S). The particle velocity is calculated by measuring the time of flight of the powder particles with a laser setup.

The etch process is usually described as the sum of many single particle impacts. When a brittle material is impacted by a hard sharp particle, the contact area is plastically deformed due to the resulting high compressive stress. This deformation leads to large tensile stresses that result in lateral cracks causing the material removal (Figure 3) and a roughness of 0.7 $2.5 \mu \mathrm{m} \mathrm{R}_{\mathrm{a}}$ (depending on the kinetic energy of the particles [13]). The etch mechanism of a single impact is thoroughly described in erosion related articles [13][14]. However, less work has been done on the characterisation of so called patterned erosion [15] as presented here.

Figure 2 shows a perspective view of a typical result of powder blasting in glass.

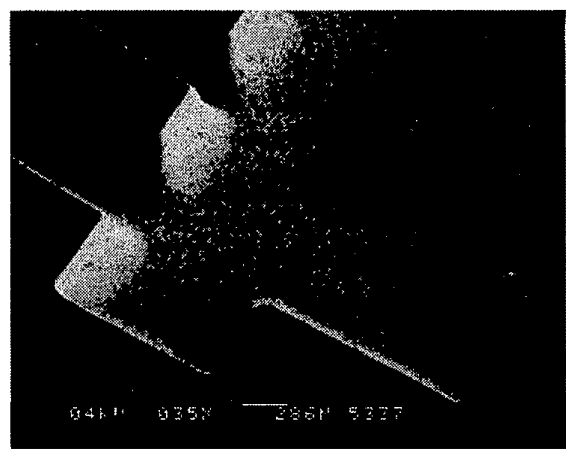

Figure 2. Perspective view of a $400 \mu \mathrm{m}$ deep channel structure in glass.

\section{MASK MATERIALS AND FEATURE SIZE}

The quality of the mask influences the performance of powder blasting. Two different kinds of mask materials can be distinguished: ductile masks and polymer masks. 


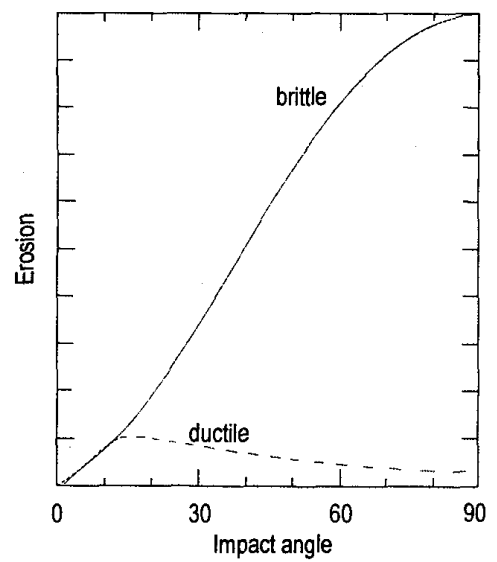

Figure 4. Two basic etch characteristics in powder blasting [12] $\left(90^{\circ}\right.$ is perpendicular impact).

Ductile materials, like metals, have a low erosion rate, especially at perpendicular impact as shown in Figure 4 (in opposite to brittle materials). This makes them suitable to be used as a mask material. Metal masks have often been used with powder blasting [1][16]. Usually, the desired design is machined in a metal plate by drilling, milling, or laser machining. When the mask plate is simply clamped on the target, particles will enter the space between the mask and the target and damage the target. Also, the impact of particles on the top surface of the plate will induce great stresses to the mask, which can result in buckling of the mask (especially with very thin plates). To solve both problems, the mask is magnetically clamped or "glued" to the target [1][16][17]. The disadvantages of this mask type are the limitations in feature size (approximately $50 \mu \mathrm{m}$ ) and pattern constraints (circular patterns cannot be used because the inside should be supported).

Elastic polymers have a high resistance because they are capable to store the kinetic energy of incoming powder particles without breaking. There are commercially available polymer negative resist foils that can be lithographically processed. This gives the possibility to make very complex and accurate masks. With such a mask a feature size of $75 \mu \mathrm{m}$ and an aspect ratio of 1.5 can easily be obtained. Unfortunately, much smaller feature sizes are not possible due to the foil properties and standard minimum thickness of $50 \mu \mathrm{m}$.

\section{Copper mask}

In order to combine the high resistance of a metal, and the high resolution of a lithographic process, we decided to apply a metal mask on the target by electroplating. Copper was chosen as the metal, because of its high resistance against powder blasting [14] and its wide use in electroplating.

Also with this metal mask, a good adhesion with the target is important, hence the intermediate titanium adhesion layer between the target and the copper. Additionally, the target is cleaned with an oxygen plasma before sputtering the metal layers. To apply a copper mask, first the whole target is covered by a titanium $(15 \mathrm{~nm}) /$ copper $(400 \mathrm{~nm})$ seed layer (Figure 5). Then, a thick resist is used as a mould in which the copper is grown. The thin seed layer beneath the resist mould is generally not removed separately, but is easily etched away by blasting.

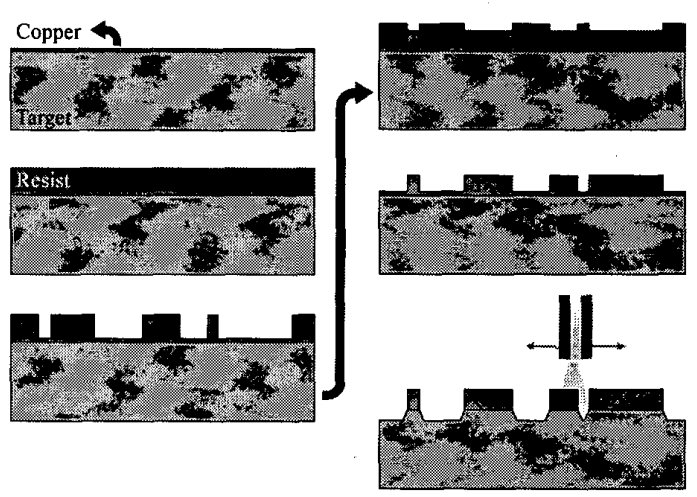

Figure 5. Applying electroplated copper as a mask.

When powder blasting with $9 \mu \mathrm{m}$ particles at a speed of $200 \mathrm{~m} / \mathrm{s}$, the selectivity of copper with Pyrex was found to be about 30, which is rather high (it can be more or less depending on the process conditions).

\section{BLAST LAG}

Machining by powder blasting creates steep sidewalls in channels. The exact reason for the initiation of the steepness is not yet completely clear. However, once it is created, the sidewalls maintain due to the impact angle dependent etch rate. The lower impact angle on the sidewalls result in a lower etch rate, with respect to the perpendicular impacts (Figure 6). During blasting, the two sidewalls of a channel grow and

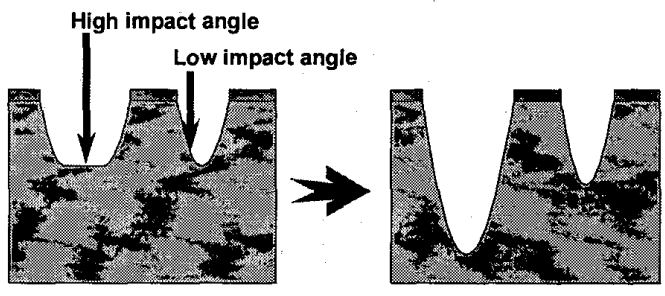

Figure 6. The formation of a blast lag. 
they evolve into a V-shape. At this point the channel only consists of sidewalls and consequently the etch rate drops. The smaller the channel, the sooner this effect occurs. So the depth of a channel also depends on the width of that channel, we call this effect the blast lag. Here, the blast lag was studied using particles with an average size of 9 to $30 \mu \mathrm{m}$.

There are some options to control and/or decrease the blast lag. The nozzle can be placed under a small angle to increase the impact angle at the sidewalls and consequently the etch rate [16]. To attack both sidewalls, another nozzle must be positioned. The blast lag decreases and you can also create a more Ushaped channel [15]. Still, the middle of the channel is etched much faster because it is exposed to two particle jets. So the effect on the blast lag is not big, especially when for complex designs, the jet must

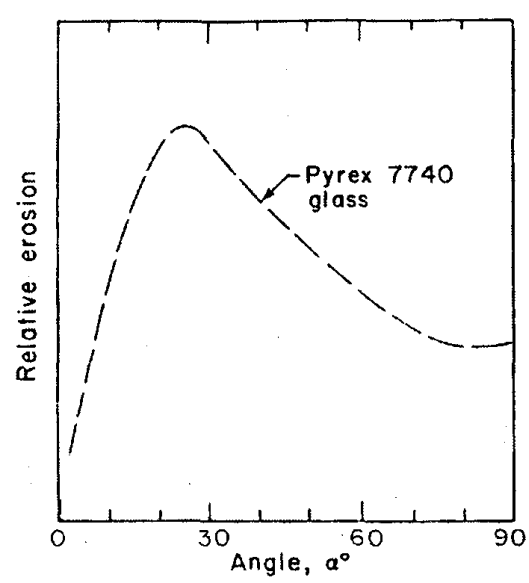

Figure 7. Ductile erosion of glass with $9 \mu \mathrm{m}$ particles at $152 \mathrm{~m} / \mathrm{s}$ (After Finnie [14]).

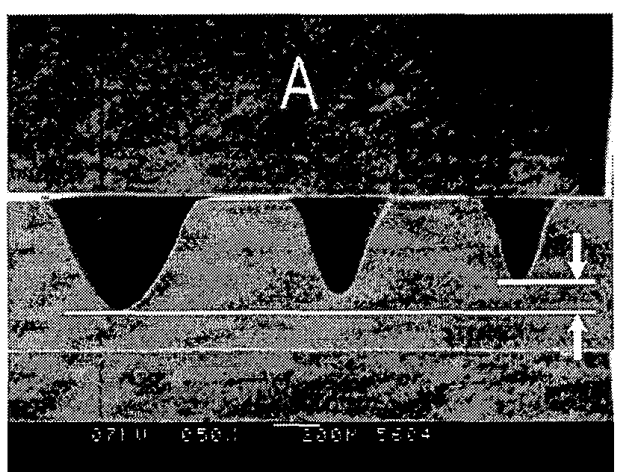

attack at lower angles from every side. Another disadvantage is the higher resist etch rate due to the lower impact angle. Also at high aspect ratios, one sidewall shields the other from the particle jet. Furthermore, the magnitude of this effect depends on the channel width.

A more elegant way to decrease the blast lag is to use smaller particles. Three advantages may be expected. First, since the smaller particles can get closer to the resist-edge, so you have a larger effective etch area (in other words a wider channel). Also, they can get closer to the bottom of the trench, thereby increasing the etch depth.

Second, a simulation of Slikkerveer [18][19] shows that by using smaller particles (analog to a smaller delta in his simulation) a different initiation of the sidewalls may be expected. This results in steeper sidewalls, which reduces the blast lag.

The use of smaller particles has a third advantage. Finnie [14] found that the impact angle dependent etch rate for $9 \mu \mathrm{m}$ particles on brittle material shows a ductile behavior (Figure 7). The reason for this is still uncertain but it results in a more effectively attack of the particles on the sidewalls compared to the attack on the bottom of the channel. Hence creating steeper sidewalls and decreasing the blast lag.

Figure 8 and Figure 9 indeed show the effect of the decreasing blast lag when using $9 \mu \mathrm{m}$ particles. Additional research is necessary to determine which of the above mentioned effect is dominant.

\section{ASPECT RATIO}

The depth of a powder blasted channel with a certain width, continuously increases during blasting. Although the etch rate decreases, as mentioned in the previous paragraph, there is no real limit to the aspect ratio, as is the case with e.g. $\mathrm{KOH}$ etching of silicon. The resist-edges have a higher erosion rate than the

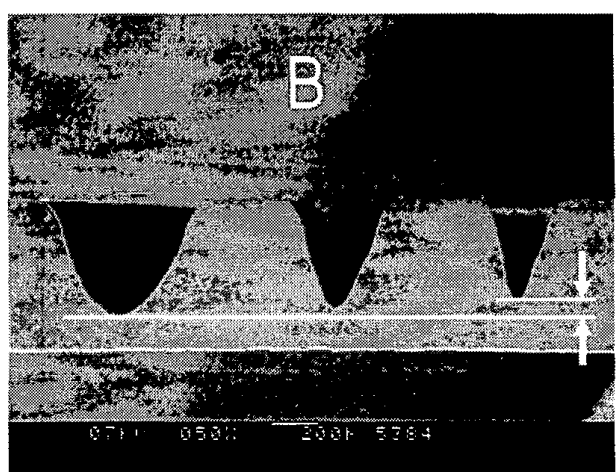

Figure 8. A: The V-shaped grooves result in a blast lag (30 $\mu \mathrm{m}$ particles). B: The blast lag effect can be reduced by using smaller particles ( $9 \mu \mathrm{m}$ particles). 


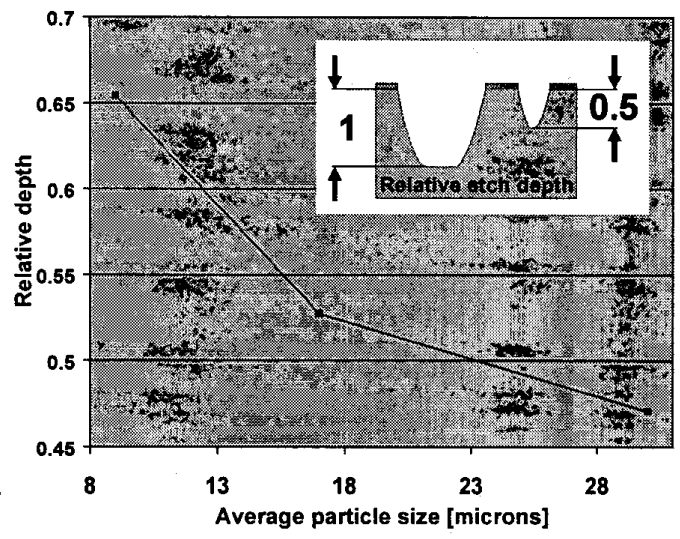

Figure 9. Decreasing blast lag of a $75 \mu \mathrm{m}$ wide channel with decreasing particle size.

bulk resist. At some point they are gradually removed and the channel becomes wider. From this point on, the aspect ratio (defined as the depth of the channel divided by its width) decreases. So an important limitation of the maximum aspect ratio is the quality of the mask. With the current available mask materials, an aspect ratio of 1.5 can easily be achieved for channels of about $75 \mu \mathrm{m}$. The aspect ratio can also be increased by trying to delay the drop in etch rate.

With the knowledge of the previous two paragraphs, we now combine the use of $9 \mu \mathrm{m} \mathrm{Al}_{2} \mathrm{O}_{3}$ particles to create very steep walls with a high resistant copper mask to be able to blast for a long time. Although these particles show a ductile etching behavior, the etch rate is still high compared to the copper etch rate. The result is shown in Figure 10. Here we see a cross-section of a $60 \mu \mathrm{m}$ wide channel with an aspect ratio of 2.5. It is blasted with alumina particles with an average size of $9 \mu \mathrm{m}$ and a velocity of $180 \mathrm{~m} / \mathrm{s}$ using a $50 \mu \mathrm{m}$ thick copper mask.

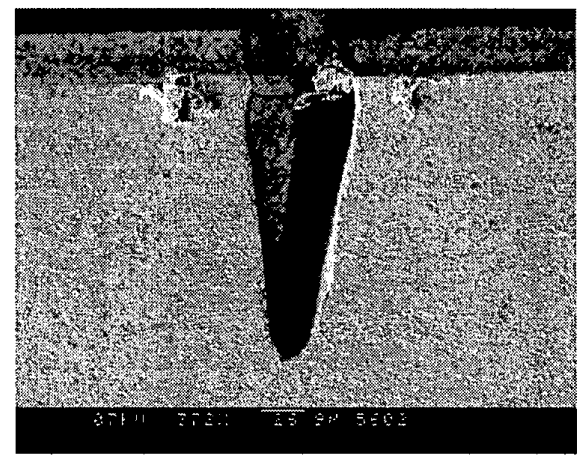

Figure 10. A $60 \mu \mathrm{m}$ wide channel with a high aspect ratio in glass (shown without mask).

\section{DISCUSSION}

There are many different mask materials for powder blasting, all with specific advantages and disadvantages. In this article we add another: electroplated copper which is characterized by its high resistance and capability of small feature sizes. This makes it possible to easily create channels of less than $50 \mu \mathrm{m}$ wide. Also, the high resistant copper enables us to do reliable research on channel profiles. The blast lag is an unwanted effect of powder blasting. However, it's possible to control the lag to a certain extend by changing the average particle size. Why smaller particles decrease the blast lag is uncertain, since several mechanisms can (simultaneously) be responsible for it. Either way, the blast lag does not disappear, so further research is required on this subject.

The profile of a channel can have three basic shapes. First a bowl shape is created until the sidewalls grow together to form a V-shaped profile. Continues blasting will lead to the third convex-concave shape [15]. This is because rebounding particles from the sidewall, impact on the bottom of the trench with a higher angle. Normally, for aspect ratio more than 1, the third shape is created. However, our high aspect ratio channel is still in its second shape (Figure 10). This is caused either by the assumed different initiation of the sidewalls because of the use of smaller particles, as simulated for brittle erosion [18][19]. Or (and more likely) by the ductile erosion characteristic of the $9 \mu \mathrm{m}$ particles we used which e.g. can cause a lower rebounding velocity.

\section{CONCLUSIONS}

Powder blasting is a directional etch technique for a wide class of materials (e.g. glass, silicon, ceramics). The technique fits very well between the common micromachining techniques due to its lithographic masking, process similarities and compatibility.

Electroplated copper was presented as a new mask for powder blasting. It combines a high resistant mask material with the high resolution of lithography, which makes it possible to obtain smaller feature sizes $(<50 \mu \mathrm{m})$.

It was observed that the blast lag (small channels etch slower compared to wider channels) is decreased by using $9 \mu \mathrm{m}$ in stead of $30 \mu \mathrm{m}$ particles. This is mainly due to the steeper sidewalls that are created with these particles.

Using the high resistance of an electroplated copper mask, and $9 \mu \mathrm{m}$ particles that create the steep walls, a channel with an aspect ratio of 2.5 was blasted in glass. 


\section{ACKNOWLEDGMENTS}

The authors like to thank P.J. Slikkerveer for useful discussions. We also thank Treibacher Schleifmittel $\mathrm{GmbH}$ [11] for the supply of alumina powders. This work is part of the research programme of the 'Stichting voor Fundamenteel Onderzoek der Materie (FOM)', which is financially supported by the 'Nederlandse Organisatie voor Wetenschappelijk Onderzoek (NWO)'.

\section{REFERENCES}

[1] Glass and glass machining in ZEUS panels, H.J. Ligthart, P.J. Slikkerveer, F.H. in 't Veld, P.H.W. Swinkels, M.H. Zonneveld, Philips J. Res., 50 (1996), pp.475-499

[2] Rapid prototyping of silicon structures by aid of laser and abrasive-jet machining, A. Kruusing, S. Leppävuori, A. Uusimäki, M. Uusimäki, SPIE proceedings, vol. 3680 (1999), pp. 870878.

[3] A sandblasting process for fabrication of color PDP phosphor screens, H. Fujii, H. Tanabe, H. Ishiga, M.Harayama, M. Oka, SID 92 digest (1992), pp. 728-731

[4] Vademecum voor de glastechniek, P. Heller, J. Vervest, H.Wilbrink, Kluwer technische boeken B.V., Deventer, The Netherlands, (1992).

[5] Review on ultrasonic machining, T.B.Thoe, D.K. Aspinwall, M.L.H. Wise, Int. J. Mach. Tools Manufact., vol. 38 (1998), pp. 239-255

[6] Non-traditional technologies for micro fabrication, P. Dario, M.C. Carrozza, N. Croce, M.C. Montesi, M. Cocco, J. Micromech. Microeng., vol. 5 (1995) pp. 64-71.

[7] R. Keoschkerjan, et al., Piezoelectric X-YMicropositioner Microfabricated from Photosensitive Glass., 10th Workshop on Micromachining, Micromechanics and Microsystems (MME 99), September 27-28, 1999, Gif-sur-Yvette, France.

[8] Glasses for microsystem technology, D. Hülsenberg, Microelectronics Journal, vol.28 (1997), pp. 419-432.

[9] Deep wet etching of borosilicate glass using an anodically bonded silicon substrate as mask, $\mathrm{T}$. Corman, P.Enoksson,G.J. Stemme, J. Micromech. Microeng. Vol. 8 (1998) pp. 84-87.

[10] $\mathrm{SiO} 2$ etching using high density plasma sources, T. Tsukada, H. Nogami, Y. Nakagawa, E. Wani, K. Mashimo, H. Sato, S. Samukawa, Thin Solid Films vol 341 (1999) pp. 84-90.

[11] Treibacher Schleifmittel GmbH, Ferroweg 1, D79725 Laufenburg, Germany, Tel. $+49.7763 .9330$
[12] Erosion of Ceramic Materials, J.E. Ritter (ed.), Trans. Tech. Publications, Zurich, Switzerland (1992)

[13] Erosion and damage by sharp particles, P.J. Slikkerveer, P.C.P. Bouten, F.H. in 't Veld, H. Scholten, Wear vol 217 (1998) pp. 237-250.

[14] Some reflections on the past and future of erosion, I. Finnie, Wear vol 186-187 (1995) pp. $1-10$.

[15] High Quality Mechanical Etching of Brittle Materials by Powder Blasting, P.J. Slikkerveer, P.C.P. Bouten, F.C.M. de Haas. Accepted for Sensors and Actuators.

[16] Powder Blasting as a New Technology for Inertial Sensor Fabrication, E. Belloy S. Thurre, E. Walckiers, A. Sayah, and M.A.M. Gijs, Eurosensors XIII (1999) pp. 827-830.

[17] Mask Materials in Powderblasting, H. Wensink, J.W. Berenschot, H.V. Jansen, M.C. Elwenspoek, 10th Workshop on Micromachining, Micromechanics and Microsystems (MME 99), September 27-28, 1999, Gif-sur-Yvette, France. pp. 199-202.

[18] Mathematical modeling of erosion by powder blasting, P.J. Slikkerveer, J.H.M. ten Thije Boonkkamp, submitted to Surveys on mathematics for industrie.

[19] Mechanical Etching of Glass by Powder Blasting, P.J. Slikkerveer, Ph.D. Thesis, Eindhoven University of Technology, The Netherlands, (1999) pp.106-114. 